\title{
The Creativity Crisis (is not) as Plain as the Nose on Your Face:
}

\section{A Few Introductory Comments}

\author{
Maciej Karwowski
}

Academy of Special Education, Poland

E-mail address: maciek.karwowski@gmail.com

ARTICLE INFO

\section{Keywords:}

Middle-range theories

Creative crisis

ISSN: 2354-0036

DOI: 10.15290/ctra.2014.01.02.01

\author{
A B S TR A C T
}

Is there a crisis in creativity science? According to the feature article (Glăveanu, 2014 - in the first issue of this journal), there can be no doubt that there is. However, as the current issue shows, there is no agreement among creativity scholars that this is the case. This editorial does not aim at providing an additional critique of Glăveanu's perspective. Instead, I rather re-iterate some previously raised arguments (Karwowski, 2012), and call for middle-range theorizing in creativity science.

Having provocative, yet thorough papers for the inaugural issue of a new journal is the dream of every editor and a gift when it happens. Hence, as we highlighted in our first editorial (Karwowski \& Uszynska-Jarmoc, 2014), we were more than happy, to open the first issue of CTRA ("Creativity: Theories - Research - Applications") with an article written by Vlad Petre Glăveanu of Aalborg University, and we are grateful for his engagement in this exchange. In his article, Glăveanu challenged the way that mainstream creativity science is functioning, seeing the psychology of creativity as a discipline in crisis. However, as the commentaries included in the current issue show, this claim is far from being obvious and widely accepted. Leading creativity scholars have devoted their time and energy to constructively criticize Glăveanu's position and have provided several fresh insights about their perceptions of the current state of the art of creativity science. As the editor I wish to thank all commentators, who responded to our call and submitted articles. It is delightful to say, that we have received almost thirty papers, focusing on different questions raised by the lead article. Following completion of the editorial process, we have decided to devote two issues of the journal (this and the next) to the presentation of these papers: a decision based on the content of the commentaries.

This issue as a whole deals with quite a general question, whether "there is really a crisis in creativity science?", and contains commentaries written by Dean Keith Simonton, Mihalyi Csikszentmihalyi and Izabela Lebuda, John Baer, Ronald Beghetto, Mathias 
Benedek and Emanuel Jauk, James Kaufman, David Cropley, Jonathan Plucker, Paul Silvia, Michal Chruszczewski, Alfonso Montuori, Roni Reiter-Palmon, Eric Shiu, as well as Vlad Glăveanu's response. Having such great scholars on board guarantees a highquality discussion: full of knowledge, but also not void of controversies. The main controversy surely lies in the perception and evaluation of the current reality of creativity science - the very general question of whether there is a crisis at all?

Most of the commentators perceive today's psychology of creativity as a flourishing field. Several commentators also disagree with the claim that more general theories in creativity science are either useful or required at all. Some time ago, commenting on another thought-provoking article of Glăveanu (2012), I argued that in the social sciences (creativity science included) middle-range theories (Merton, 1968) work best, building bridges between theoretical ideas and research results, and allowing the development of empirically testable theories, instead of often unfalsifiable grand theories (Karwowski, 2012). Wide, grand theories (Baer, 2011) are sometimes useful as paradigm-builders, but simultaneously are rarely testable and - as a result - too often end by being more a kind of ideology in science than the science itself. Rarely, for sure too rarely, grand theories are effectively translated into research programs - the only one, relevant to creativity, which comes to my mind at this moment is Campbell-Simonton's Blind Variation Selective Retention Theory, which has been vigorously tested, thanks to the continuous work of Dean Simonton (1998, 1999, 2011, see also Simonton, this issue). More generally however, grand theories are often much more fruitless than scholars - especially those humanistically oriented - would ever admit. Quite the opposite is observed in the case of middle-range theories - theoretical models which are well-operationalized, and possible to re-organize effectively. Even wide theoretical models, like James Kaufman's and Ron Beghetto's "Four-C Model of Creativity" (Kaufman \& Beghetto, 2009), could be translated into a number of empirically testable hypotheses, allowing us better understanding not only of the relationship between different forms and levels of creativity, but also the pathway from creative potential (mini-c and little-c) to creative achievement. Hence, my personal opinion has not changed, and I still think that creativity science works as normal science does (Kuhn, 1962): usually focusing much more on small-level incremental changes and improvements, than revolutionary changes and huge discoveries. It is somehow paradoxical, that although laypeople and experts perceive creativity as quite a revolutionary activity, the great majority of creativity scholars work more as adaptors than innovators - using the well-known Kirton (1976) distinction, or more as experimentalists than conceptualists - to use Galenson's (2009) terms. We add small 
bricks of results and ideas to the building of the creativity literature. But to flourish, the field needs conceptualists and experimentalists, adaptors and innovators. Vlad Petre Glăveanu, without any doubt, is an innovator and conceptualist in the field. Indeed, in his extensively published work, he not only criticizes the status quo of creativity science (Glăveanu, 2012, 2014), but also proposes several new and interesting theoretical ideas (Glăveanu, 2010, 2012a, 2013, in press), which enrich our understanding of creativity as a social phenomenon and may form an inspiration for ambitious empirical projects.

It may be the case that, when scholars in the certain field of science focus more on discussing the field's condition, than spending their time on research, it is likely to be devastating for this area of research. On the other hand however, in creativity science and in our journals, we too rarely discuss this status quo from the meta-perspective (see for instance Makel, 2014; Richards \& de Cock, 1999). Thus, it is the great pleasure of the whole CTRA team, to have such an exchange of perspectives in the pages of our journal. We wish our readers enjoyment and new insights, while reading it. And finally, we would like to end with the reminder that this is not the last word on the subject - the forthcoming issue (1) of volume 2, to be published in early 2015 will contain commentaries by such scholars as Mark Runco, Beth Hennessey, Seana Moran, Todd Lubart and Xavier Carroff, Anatoliy Kharkhurin, Jacek Gralewski, Anna Hui, Katarzyna Citko, Min Tang, Ai-Girl Tan, Eva Hoff and Ingegerd Carlsson, Roland Persson, Lene Tanggaard, and Brady Wagoner, as well as Glăveanu's response to this set of commentaries.

While wishing our readers, authors, and friends happy holidays and a productive New Year in 2015, we would like to invite and encourage scholars from all over the world to submit their theoretical work, research articles, as well as examples of creative practice to CTRA. Let us build this new journal together.

\section{REFERENCES}

Baer, J. (2011). Why grand theories of creativity distort, distract, and disappoint. International Journal of Creativity and Problem Solving, 21, 73-100.

Galenson, D.W. (2009). Old masters and young geniuses: The two life cycles of human creativity. Journal of Applied Economics, 12, 1-9.

Glăveanu, V.P. (2014). The psychology of creativity: A critical reading. Creativity: Theories - Research - Applications, 1, 10-33, DOI: 10.15290/ctra.2014.01.01.02.

Glăveanu, V.P. (2013). Rewriting the language of creativity: The Five A's framework. Review of General Psychology, 17, 69-81.

Glăveanu, V.P. (2012). From dichotomous to relational thinking in the psychology of creativity: A review of great debates. Creativity and Leisure: An Intercultural and Cross-disciplinary Journal, 1, 83-97. 
Glăveanu, V.P. (2012a). Habitual creativity: revising habit, reconceptualizing creativity. Review of General Psychology, 16, 78-92.

Glăveanu, V.P. (2010). Paradigms in the study of creativity: Introducing the perspective of cultural psychology. New ldeas in Psychology, 28, 79-93.

Glăveanu, V.P. (in press). Creativity as a sociocultural act. Journal of Creative Behavior. Karwowski, M. (2012). Middle and grand theorizing in the psychology of creativity. Creativity and Leisure: An Intercultural and Cross-disciplinary Journal, 1, 109-115.

Karwowski, M. \& Uszynska-Jarmoc, J. (2014). Creativity: The show must go on. Creativity: Theories - Research - Applications, 1, 4-9, DOI: 10.15290/ctra.2014.01.01.01.

Kaufman, J.C., \& Beghetto, R.A. (2009). Beyond big and little: The Four C Model of Creativity. Review of General Psychology, 13, 1-12.

Kirton, M. (1976). Adaptors and innovators: A description and measure. Journal of Applied Psychology, 61, 622-629.

Kuhn, T.S. (1962) The Structure of scientific revolutions, Chicago: University of Chicago Press.

Makel, M.C. (2014). The empirical march: Making science better at self-correction. Psychology of Aesthetics, Creativity, and the Arts, 8, 2-7.

Merton, R.K. (1968). Social theory and social structure. New York: Free Press.

Rickards, T. \& De Cock, C. (1999). Sociological paradigms and organizational creativity. In R.E. Purser \& A. Montuori (Eds.). Social creativity (vol. II, pp. 235-257). Cresskill, NJ: Hampton Press.

Simonton, D.K. (1998). Donald Campbell's model of the creative process: Creativity as blind variation and selective retention. Journal of Creative Behavior, 32, 153-158.

Simonton, D.K. (1999). Creativity as blind variation and selective retention: Is the creative process Darwinian? Psychological Inquiry, 10, 309-328.

Simonton, D.K. (2011). Creativity and discovery as blind variation and selective retention: Multiple-variant definitions and blind-sighted integration. Psychology of Aesthetics, Creativity, and the Arts, 5, 222-228.

Corresponding author at: Maciej Karwowski, Department of Educational Sciences, Academy of Special Education, 40 Szczesliwicka St., 02-353 Warsaw, Poland.

E-mail: maciek.karwowski@gmail.com 